\title{
An Evaluation of Serum Procalcitonin and C-Reactive Protein Levels as Diagnostic and Prognostic Biomarkers of Severe Sepsis
}

\author{
Janos Szederjesi ${ }^{1 *}$, Emoke Almasy ${ }^{1}$, Alexandra Lazar ${ }^{1}$, Adina Huțanu², Iudita Badea ${ }^{1}$, Anca \\ Georgescu ${ }^{3}$ \\ 1 Department of Anesthesiology and Intensive Care, University of Medicine and Pharmacy Tirgu Mures, Romania \\ ${ }^{2}$ County Clinical Emergency Hospital Tirgu Mures, Romania \\ ${ }^{3}$ Department of Infectious Diseases, University of Medicine and Pharmacy Tirgu Mures, Romania
}

\begin{abstract}
Background: Recommendations have been made, following the multicenter Surviving Sepsis Campaign study, to standardize the definition of severe sepsis with reference to several parameters such as haemodynamic stability, acid-base balance, bilirubin, creatinine, International Normalized Ratio (INR), urine output and pulmonary functional value of the ratio between arterial oxigen partial pressure and inspiratory oxigen concentration. Procalcitonin (PCT) is considered to be a gold standard biomarker for the inflammatory response, and recent studies have shown that it may help to discover whether a seriously ill person is developing sepsis. C-reactive protein (CRP) is also used as a marker of inflammation in the body, as its blood levels increase if there is any inflammation in the body. The aim of this study was to evaluate serum procalcitonin and C-reactive protein levels as diagnostic and prognostic biomarkers of severe sepsis.
\end{abstract}

Material and method: Sixty patients, diagnosed as being "septic", were admitted to the intensive care unit (ICU). Based on laboratory results and clinical findings a diagnosis of "severe sepsis" was made, and correlated with PCT and CRP values. The APACHE II, SAPS II and SOFA severity scores were calculated, analyzed and correlated with PCT and CRP.

Results: Fifty two patients (86.67\%) presented with criteria for severe sepsis. Multivariate correlation analysis indicated a significant positive association between procalcitonin and all severity scores (APACHEII $p<0.0001$, SOFA $p<0.0001$, SAPS II $p<0.0001)$. CRP proved to be significantly correlated only with the SAPS II score $(p=0.0145)$. Mortality rate was high, with 48 patients (80\%) dying. There was no significant correlation between the levels of the PCT and CRP biomarkers and severe sepsis ( $p=0.2059$ for PCT, $p=0.6059$ for CRP).

Conclusions: The procalcitonin levels are highly correlated with the severity scores (APACHE II, SAPS II, SOFA) regularly used in ICUs and therefore can be used for determining the severity of the septic process. Quantitive procalcitonin and C-reactive protein analysis was not shown to be useful in diagnosing severe sepsis. However, PCT and CRP can be used to predict the fatal progression of the septic patient.

Keywords: severe sepsis, procalcitonin, C-reactive protein, prognostic biomarkers

Received: 16 July 2015 / Accepted: 01 September 2015

\section{INTRODUCTION}

Sepsis is a systemic inflammatory response (SIRS) of the host to several infections. It can lead to severe sepsis which remains a principal cause of death in Intensive Care Units (ICU) worldwide, with one in four patients dying of severe sepsis or septic shock [1-5].
The early diagnosis and decided management can lead to lower mortality rates and improved outcomes [6].

Recent studies have focused on the use of an ideal biomarker for the diagnosis and prognostic of sepsis [7-9]. Of the many studied biomarkers, procalcitonin

\footnotetext{
Correspondence to: Janos Szederjesi, University of Medicine and Pharmacy Tirgu Mures, Romania, Department of Anesthesiology and Intensive Care, 38 Gheorghe Marinescu, Tirgu Mures, 540139, Romania. E-mail: yangzi37@gmail.com

Emoke Almasy: University of Medicine and Pharmacy Tirgu Mures, Romania, Department of Anesthesiology and Intensive Care, 38 Gheorghe Marinescu, Tirgu Mures, 540139, Romania Alexandra Lazar: University of Medicine and Pharmacy Tirgu Mures, Romania, Department of Anesthesiology and Intensive Care, 38 Gheorghe Marinescu, Tirgu Mures, 540139, Romania Adina Huțanu: County Clinical Emergency Hospital Tirgu Mures, Romania, 50 Gheorghe MarinescuTirguMures, 540139, Romania

ludita Badea: University of Medicine and Pharmacy Tirgu Mures, Romania, Department of Anesthesiology and Intensive Care, 38 Gheorghe Marinescu, Tirgu Mures, 540139 , Romania Anca Georgescu: University of Medicine and Pharmacy Tirgu Mures, Romania, Department of Infectious Diseases, 38 Gheorghe Marinescu, Tirgu Mures, 540139 , Romania
} 
remains the gold standard for sepsis diagnosis, and is considered by some clinicians to be an indicator of the severity of clinical sepsis [10].

$\mathrm{C}$ reactive protein is another biomarker used to diagnose both chronic and acute inflammatory responses. In patients diagnosed as having sepsis or septic shock, it may be used to establish the severity of these conditions and in the same time to establish a prognosis $[11,12]$.

In 2013 a large multicenter study (Surviving Sepsis Campaign) was conducted targeting the septic patient, with the aim of establishing new definitions and management for sepsis. The Surviving Sepsis Campaign lists the main criteria for defining both sepsis and severe sepsis. According to these guidelines, sepsis is defined as "the presence (probable or documented) of infection together with systemic manifestations of infection", while severe sepsis is defined as "sepsis plus sepsis-induced organ dysfunction or tissue hypoperfusion" $[6,13,14]$.

For the diagnosis of sepsis, the systemic inflammatory response criteria remain mostly unchanged including general variables such as fever $\left(>38.3^{\circ} \mathrm{C}\right)$ or hypothermia $\left(<36^{\circ} \mathrm{C}\right)$, tachycardia $>90 / \mathrm{min}$, tachypnea, altered mental status, significant edema or positive fluid balance (>20 mL/kg over $24 \mathrm{hr}$ ). The laboratory criteria used include hyperglycemia ( $>140 \mathrm{mg} / \mathrm{dL}$ ), leukocytosis $(>12,000 / \mu \mathrm{L})$ or leukopenia $(<4000 / \mu \mathrm{L})$, $\mathrm{C}$-reactive protein and procalcitonin levels, both more than twice the normal value [6].

To arrive at a diagnosis of severe sepsis the presence of the following criteria were advocated: sepsis-induced hypotension, metabolic acidosis with high lactate, urine output $<0.5 \mathrm{~mL} / \mathrm{kg} / \mathrm{h}$, acute lung injury with $\mathrm{PaO} 2 / \mathrm{FIO} 2<200$, creatinine $>2.0 \mathrm{mg} / \mathrm{dL}$, bilirubin $>2$ $\mathrm{mg} / \mathrm{dL}$, platelet count $<100,000 / \mu \mathrm{L}$, international normalized ratio INR $>1.5$ [7].

Procalcitonin (PCT) and $\mathrm{C}$ reactive protein (CRP) values are considered to be of paramount importance for a diagnosis of sepsis, but there is lack of evidence about the role of these two markers in severe sepsis and in arriving at a prognosis following a diagnosis of severe sepsis, with reference to the new definitions as stated in the Surviving Sepsis Campaign study.

\section{Aim of study}

The aim of this study is to investigate the utilization of procalcitonin and $\mathrm{C}$ reactive protein levels in the diagnosis of severe sepsis and to determine their potential prognostic roles.

\section{MATERIAL AND METHODS}

A prospective study was conducted in the Clinic of Intensive Care of the County Clinical Emergency Hospital Tîrgu Mureș from January to November 2014. The approval of the Ethics Committee of the University of Medicine and Pharmacy of Tîrgu Mureș was obtained prior to the commencement of the study. Written informed consent was obtained from all participants or their relatives before including them into the study.

Inclusion criteria: All adult ( $>18$ years) admitted to the ICU with SIRS, presenting with at least two positive criteria for sepsis, and who had not received any surgical intervention in the previous seventy two hours or had cardiac arrest or trauma, were admitted into the study.

Exclusion criteria: Adult ( $>18$ years) patients with non-infectious SIRS, admitted to the ICU during the same time period.

Patients were diagnosed with sepsis using the following standard clinical criteria: temperature: fever $\left(>38.3^{\circ} \mathrm{C}\right)$ or hypothermia $\left(<36^{\circ} \mathrm{C}\right)$, heart rate over $90 /$ min, respiratory status: tachipnoe over $24 \mathrm{resp} / \mathrm{min}$ or mechanically ventilated, haemodynamic status: systolic blood pressure under $90 \mathrm{mmHg}$ after fluid resuscitation and leukocyte count: leukocytosis $(>12,000 / \mu \mathrm{L})$ or leukopenia $(<4000 / \mu \mathrm{L})$.

Sepsis was defined as present when at least two of the criteria for the systemic inflammatory response syndrome (SIRS) and clinical or microbiological evidence infection were present.

Sixty eight patients presented with a diagnose of SIRS and of these sixty, aged between 20 and 90 years, were diagnosed with a proven infection. Eight patients were excluded due to lack of confirmation of an infectious etiology of SIRS. Out of sixty patients, thirty one (51.67\%) were females and twenty nine (48.33\%) males.

On admission to the ICU, a medical history was taken, the clinical status was monitored and recorded, including blood pressure, diuresis, SpO2, ECG and ventilation parameters such as current volume, respiratory rate and ventilation mode. Laboratory tests included leucocytes, platelets counts, creatinine, urea, INR, bilirubin and bacteriological determinations. Blood cultures were performed. The APACHE II (Acute Physiology and Chronic Health Evaluation), SOFA (Sequential Organ Failure Assessment) and SAPS II (Simplified Acute Physiology Score) severity scores were calculated. 
The criteria for the severe sepsis in the study group are presented in Table 1.

Within twelve hours of being admitted to the ICU, blood samples were obtained via vascular puncture for PCT and CRP analysis and stored in serum tubes without anticoagulant. The samples were centrifuged and the serum were collected and frozen at $-70^{\circ} \mathrm{C}$ for later processing. Blood cultures were attained using separate vials for aerobic (Standard SA) and anaerobic (Standard SN) organisms. Analyses of the blood cultures were processed using the BacT/Alert 3D (Biomerieux, France) automated hemoculture system.

PCT, CRP and the sepsis-related organ failure assessment (SOFA) were determined using the immuneturbidimetry method (Cobas 6000, Roche Diagnostics, Germany) and Promo Kinekits (PromoCell GmbH, Heidelberg, Germany) for the detection, elimination and prevention of cell culture contamination.

The antropometric characteristics of the patients were measured and the body mass index (BMI) was calculated. The correlations between BMI and both PCT and CRP levels were determined, as was the correlation between BMI, death and severe sepsis presence.

Surviving patients were seen six months after admission to the ICU and the outcomes were recorded.

Statistical analysis was performed using Microsoft Excel (Microsoft, Washington, USA), GraphPad (GraphPad Software, Inc., California, USA) and MedCalc (MedCalc Software, Ostend, Belgium).

Analysis included specificity and sensibility of PCT and CRP for diagnosis of severe sepsis, and correlation with death. Graphic representation of receiveroperating-characteristic (ROC) were used, with deter-

\section{Table 1. Severe sepsis criteria}

\section{Criteria}

N (\%)

\begin{tabular}{|c|c|}
\hline Without severe sepsis & $8(13.33 \%)$ \\
\hline Severe sepsis & $52(86.67 \%)$ \\
\hline Hypotension* & 18 \\
\hline Metabolic acidosis ** & 23 \\
\hline Urine output $<0.5 \mathrm{~mL} / \mathrm{kg} / \mathrm{hr}$ & 17 \\
\hline Acute lung injury with $\mathrm{PaO} 2 / \mathrm{FIO} 2<200$ & 30 \\
\hline Creatinine $>2.0 \mathrm{mg} / \mathrm{dL}$, & 22 \\
\hline Bilirubin $>2 \mathrm{mg} / \mathrm{dL}$, & 3 \\
\hline Platelet count $<100,000 / \mu \mathrm{L}$, & 5 \\
\hline International normalized ratio INR >1.5 & 18 \\
\hline
\end{tabular}

mination of area under the curve (AUC). Quantitative variables were tested for normal distribution using the Kolmogorov-Smirnov test and Bartlett's Test for equal variances. Where applicable the Mann-Whitney or Pearson tests were used for variable correlations. Pearson's chi2 test with Fisher or Yates correction were used to compare the distribution of nominal values. A significance level of alpha $(\alpha)=0.05$ was applied.

\section{RESULTS}

The demographic and clinical characteristics of the group are represented in Table 2.

Sixty patients met the criteria for sepsis and of these fifty two $(86.67 \%)$ presented criteria for severe sepsis.

Thirty patients $(57.69 \%)$ with severe sepsis were further identified with acute lung injury, twenty three patients (44.23\%) with metabolic acidosis, twenty two $(42.3 \%)$ with elevated serum creatinine levels, and eighteen patients (34.61\%) were hypotensive.

The mean serum PCT level in the severe sepsis group (86.67\%) was $1.367 \pm 2.437 \mathrm{ng} / \mathrm{mL}$, and the mean serum CRP level $172 \pm 124.1 \mathrm{ng} / \mathrm{mL}$.

No significant correlations were found between laboratory assays (PCT, CRP,INR, PLT, Bi) and severe sepsis (Table 3).

Positive blood cultures were found in $16.66 \%$ of patients. The commonest site of infection was the lungs (41 patients) (Table 4).

According to multivariate correlation analysis, there was a significant positive association between procalcitonin serum levels and all severity scores (APACHE II $\mathrm{p}<0.0001$, SOFA $\mathrm{p}<0.0001$, SAPS II $\mathrm{p}<0.0001)$. There was no significant correlation between CRP and SOFA score $(\mathrm{p}=0.2889)$, but there was a significant positive association with APACHE II $(\mathrm{p}=0.0058)$ and SAPS II $(\mathrm{p}=0.0145)$.

Mortality rate was high for all septic patients, forty eight patients deceased within 7 weeks of being admitted to the study (80\%). The patients presented, too, several associated pathologies (Table 5). The survival rate was higher for those patients without severe sepsis criteria, $62.5 \%$ of patients without severe sepsis criteria surviving versus $13.46 \%$ of patiets with severe sepsis criteria. (Figure 1).

No significant correlation was found between the serum levels of PCT ( $\mathrm{p}=0.2059)$ or CRP $(\mathrm{p}=0.6059)$ and severe sepsis. 
Table 2. Demographic and clinical characteristic of the septic patients

\begin{tabular}{|c|c|c|c|c|c|c|}
\hline & Minimum & Maximum & Mean & Std. Deviation & Skewness & Kurtosis \\
\hline Age (years) & 20 & 90 & 69.27 & 15.28 & -1.326 & 1.86 \\
\hline $\mathrm{BMI}(\mathrm{kg} / \mathrm{m} 2)$ & 17.8 & 46.9 & 26.7 & 5.99 & 1.239 & 2.136 \\
\hline TI days & 0 & 42 & 8.1 & 9.24 & 1.783 & 2.874 \\
\hline MV days & 0 & 34 & 5.61 & 7.20 & 2.273 & 5.316 \\
\hline APACHE II & 10 & 50 & 27.6 & 8.54 & 0.5398 & 0.1158 \\
\hline SOFA & 0 & 16 & 8.15 & 3.45 & 0.1336 & -0.333 \\
\hline SAPS II & 15 & 90 & 47.68 & 18.93 & 0.5062 & -0.4605 \\
\hline INR & 0.99 & 4.4 & 1.49 & 0.59 & 3.288 & 12.76 \\
\hline Urea (mg/dl) & 1.99 & 452 & 110.6 & 89.37 & 1.478 & 2.838 \\
\hline Creatinine (mg/dl) & 0.24 & 14.55 & 2.43 & 2.64 & 2.405 & 7.316 \\
\hline WBC $(1000 *$ count $/ \mu l)$ & 2.8 & 57.6 & 19.8 & 11.43 & 1.525 & 2.498 \\
\hline Hct (\%) & 12.8 & 57.9 & 34.48 & 9.37 & 0.1685 & -0.2682 \\
\hline $\mathrm{Hgb}(\mathrm{mg} / \mathrm{dl})$ & 4.41 & 18 & 11.07 & 2.87 & 0.1311 & -0.2663 \\
\hline AST (mg/dl) & 7 & 860 & 76.15 & 135.2 & 4.012 & 19.53 \\
\hline $\mathrm{ALT}(\mathrm{mg} / \mathrm{dl})$ & 10 & 492 & 79.55 & 100.6 & 2.613 & 6.927 \\
\hline $\mathrm{CRP}(\mathrm{ng} / \mathrm{ml})$ & 1.96 & 545.2 & 170 & 124.1 & 1.205 & 1.227 \\
\hline РCT (ng/ml) & 0.00196 & 13.24 & 1.34 & 2.43 & 3.384 & 12.99 \\
\hline $\mathrm{Bi}(\mathrm{mg} / \mathrm{dl})$ & 0.25 & 4 & 0.94 & 0.80 & 2.809 & 8.5 \\
\hline Plt $(1000 *$ count $/ \mu \mathrm{l})$ & 75 & 555 & 238.8 & 119.9 & 0.8479 & 0.01687 \\
\hline $\begin{array}{l}\text { BMI= Body Mass Index } \\
\text { TI days = days of intensive care } \\
\text { MV days = mechanical ventilation days } \\
\text { APACHE II = Acute Physiology and Chronic } \\
\text { Health Evaluation }\end{array}$ & \multicolumn{2}{|c|}{$\begin{array}{l}\text { SOFA = Sepsis-related Organ Failure Assess- } \\
\text { ment } \\
\text { SAPS II = Simplified Acute Physiology Score } \\
\text { INR = International normalized ratio } \\
\text { WBC = white blood cell count }\end{array}$} & \multicolumn{2}{|c|}{$\begin{array}{l}\text { Hct }=\text { hematocrit } \\
\mathrm{Hgb}=\text { hemoglobin } \\
\mathrm{AST}=\text { aspartate aminotransferase } \\
\mathrm{ALT}=\text { alanine aminotransferase } \\
\mathrm{CRP}=\mathrm{C} \text {-reactive protein }\end{array}$} & \multicolumn{2}{|l|}{$\begin{array}{l}\mathrm{PCT}=\text { procalcitonin } \\
\mathrm{Bi}=\text { bilirubin } \\
\mathrm{PIt}=\text { platelet count }\end{array}$} \\
\hline
\end{tabular}

Table 3. Severe sepsis laboratory findings

\begin{tabular}{lccccc} 
& \multicolumn{2}{c}{ Severe sepsis $(\mathbf{n = 5 2})$} & \multicolumn{2}{c}{ Without severe sepsis $(\mathbf{n = 8})$} & Std. Deviation \\
\cline { 2 - 5 } & Mean & Std. Deviation & Mean & 0.42 & 0.1874 \\
\hline $\mathrm{Bi}$ & 0.98 & 0.84 & 275.8 & 65.64 & 0.0970 \\
\hline $\mathrm{Plt}$ & 233.1 & 125.7 & 1.25 & 0.15 & 0.2094 \\
\hline INR & 1.53 & 0.63 & 0.83 & 0.50 & 0.0102 \\
\hline Creatinine & 2.67 & 2.76 & 156.7 & 125.8 & 0.6059 \\
\hline PCT & 172 & 124.9 & 1.17 & 2.49 & 0.2059 \\
\hline
\end{tabular}

$\mathrm{Bi}=$ bilirubin $\quad \mathrm{Plt}=$ platelet count $\quad \mathrm{INR}=$ International normalized ratio $\quad C R P=C$-reactive protein $\quad \mathrm{PCT}=$ procalcitonin

Table 4. Localization of infectious process

\begin{tabular}{lc} 
Site of infection & Patients (n) \\
Pulmonar & 41 \\
\hline Abdominal cavity & 8 \\
\hline Cutanat & 5 \\
\hline Urinary tract & 4 \\
\hline Central nervous system & 1 \\
\hline Undefined & 1 \\
\hline
\end{tabular}

Table 5. List of associated pathology of our group $f$ patients

\begin{tabular}{ll} 
Pathology & N \\
hypertension & 27 \\
\hline cardiac failure & 19 \\
\hline chronic renal disfunction & 14 \\
\hline diabetes & 13 \\
\hline cerebral vascular disease & 7 \\
\hline COPD & 6 \\
\hline chronic hepatic disfunction & 3 \\
\hline COPD $=$ chronic obstructive pulmonary disease \\
Figure 1. Survival curve at 6 months for patients with severe sepsis vs sepsis
\end{tabular}




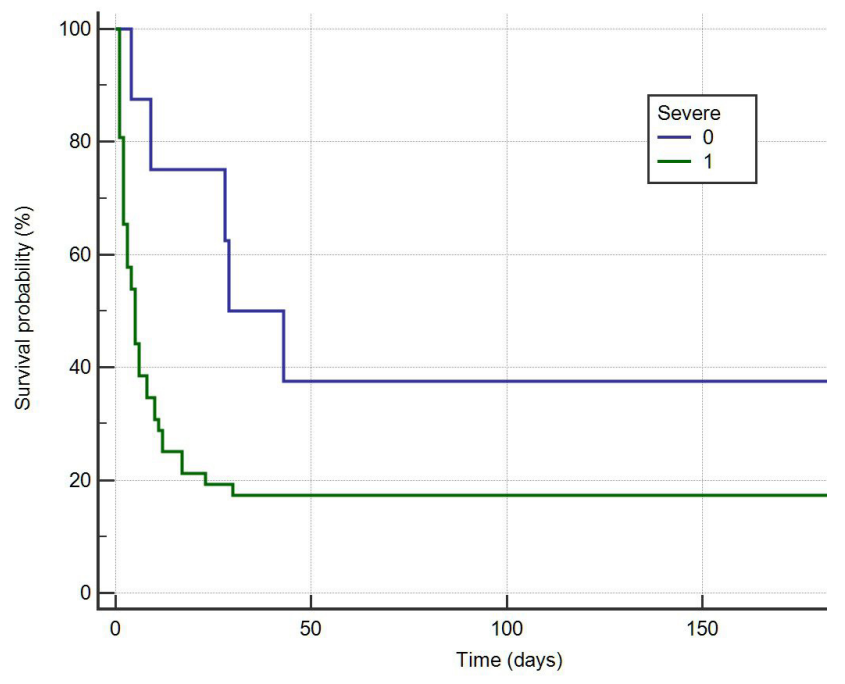

Figure 1. Survival curve at 6 months for patients with severe sepsis vs sepsis

A significant correlation existed between the death rate and serum levels of PCT $(\mathrm{p}=0.0180)$ or CRP $(\mathrm{p}=0.0195)$. A graphic interpretation of the comparative ROC curves for PCT, CRP and severity scores is represented by Figure 2 .

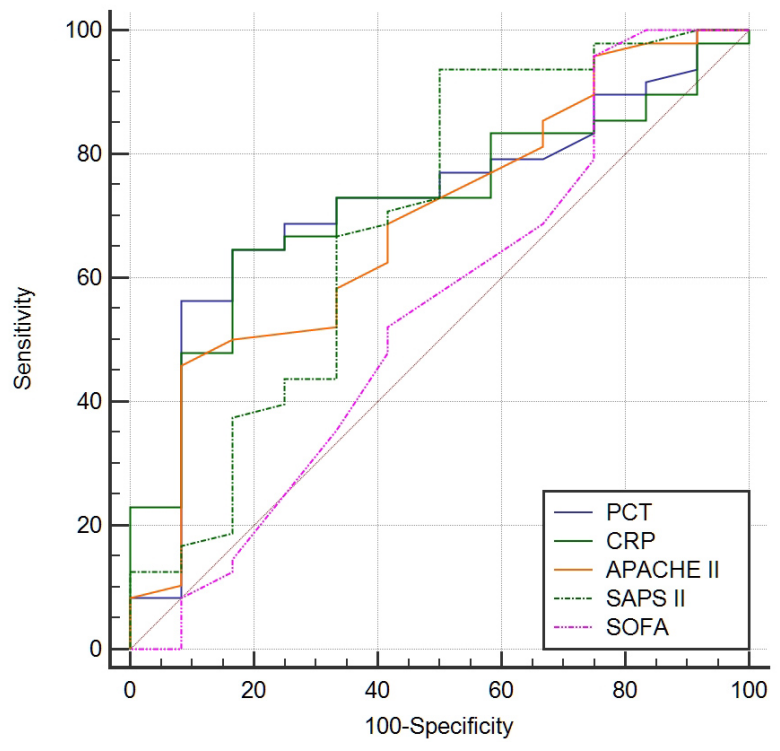

\begin{tabular}{cccccccc} 
& AUC & Sensitivity & Specificity & P value & $\begin{array}{c}\text { Cut off } \\
\text { value* }\end{array}$ & SE \\
PCT & 0.720 & 64.58 & 83.33 & 0.0065 & 0.2576 & 0.0807 \\
\hline CRP & 0.717 & 64.58 & 83.33 & 0.0036 & 121.65 & 0.0746 \\
\hline APACHE_II & 0.689 & 45.83 & 91.67 & 0.0284 & 28 & 0.0863 \\
\hline SAPS_II & 0.692 & 50.00 & 93.75 & 0.0543 & 27 & 0.0997 \\
\hline SOFA & 0.546 & 25.00 & 95.83 & 0.6653 & 3 & 0.106 \\
\hline *From Youden index & & & & &
\end{tabular}

Figure 2. Comparative ROC curves for PCT, CRP, APACHE II, SAPS II and SOFA for predicting mortality
Correlation analysis showed no significant association between BMI and PCT levels ( $\mathrm{p}=0.2473$ ).

Neither was there a significant correlation found between BMI and severe sepsis $(\mathrm{p}=0.419)$ or between BMI and mortality $(\mathrm{p}=0.3512)$. However there was a significant correlation between BMI and CRP serum levels $(\mathrm{p}=0.02)$.

A positive correlations existed between the white blood cell count and CRP serum levels ( $\mathrm{p}=0.0418)$, but not between the white blood cell count and PCT serum levels $(\mathrm{p}=0.3427)$.

\section{DISCUSSIONS}

Data are lacking on the precise role of PCT and CRP in diagnosing severe sepsis and for their potential use as a prognostic indicator in cases of the severe sepsis.

There was no significant difference of mean serum PCT and CRP values between those cases with severe sepsis versus patients with sepsis. This is in agreement with results of other studies [15].

The present study is also in agreement with previous data which shoes that respiratory infections are invariably the most common cause of sepsis and severe sepsis [15]. Ventilator acquired pneumonia is a common cause of intensive care infections worldwide [16]. Cutaneous infections were also common in our study (5 patients, $8.3 \%$ ), patients presenting several pressure ulcers. One of the most important determinant factor for pressure ulcers is the difficulty of adequate mobilization of the patients due to several associated conditions such as mechanical ventilation, pathologies which requires immobilization, deep coma or high sedation.

Haemocultures revealed a high rate of nosocomial infections among our group. Seven patients (70\%) out of 10 positive haemocultures were found to have Staphyloccocus Methicilin Resitant (MRSA) $(n=3)$, Acinetobacter $(n=2)$, KlebsiellaPenumonie $(n=3)$ and Pseudomonas Aeruginosa $(n=2)$. One patient was identified to present simultaneously with positive haemocultures of Staphylococcus Aureus MRSA (Methilicilin resistant) and Pseudomonas Aeruginosa, one patient with Staphylococcus Aureus MRSA and Klebsiella Pneumonie and another one with Pseudomonas Aeruginosa and Klebsiella Pneumonieplus Acinetobacter. One of the most frequently observed severe infection was with MRSA, a fact also observed by other authors [17]. 
The data from the present study indicated that PCT and CRP serum levels have a prognostic value for death rate (PCT $\mathrm{p}=0.0180, \mathrm{CRP} \mathrm{p}=0.195)$. PCT is correlated with the severity scores APACHE II $(\mathrm{p}<0.0001)$, SOFA $(\mathrm{p}<0.0001)$ and SAPS II $(\mathrm{p}<0.0001)$, and is in agreement with previously recorded findings [18].

The high mortality rate in the present study may be explained by the severe status of the patients who had a mean APACHE II value $27.6 \pm 8.54$, with fifty two of the patients (86.67\%) above the value of 19 , most of them presenting various severe associated pathology (Table 5).

The serum levels of PCT and CRP were measured within twenty four hours of admission and this corresponded with previous studies [19].

There was no significant correlation between PCT and CRP levels and the presence of severe sepsis, the ROC curve analysis revealed an AUC of 0.641 for PCT and of 0.558 for CRP, therefore the use of these biomarkers for establishing the diagnosis of severe sepsis should not be recommended. For predicting the prognosis of sepsis both biomarkers proved to be accurate, and our data indicated a cut off value of $0.2576 \mathrm{ng} / \mathrm{ml}$ for PCT and $121.65 \mathrm{ng} / \mathrm{ml}$ for CRP in predicting a fatal outcome for patients (Figure 2).

In the present study, the survival rate was higher for those patients not diagnosed with severe sepsis. Other studies indicated that patients with clinical criteria for severe sepsis but without positive blood cultures died, and patients with a documented infection are at similarly high risk of death [20].

Regarding the significant correlation between CRP and BMI $(\mathrm{p}=0.0201)$, this has been also reported previously in a group of young healthy individuals $[21,22]$.

The serum levels of PCT and CRP are very highly correlated $(p<0.0001)$ and as both of them are biomarkers of inflammation, this finding is to be expected. However the high correlation between PCT serum levels and APACHE II, SAPS II and SOFA severity scores in parallel with the lack of correlation between CRP serum levels and SOFA severity score, suggests the superiority of PCT for assessing the severity of the septic patients, and this is in agreement within previously stated conclusions $[23,24]$.

\section{CONCLUSIONS}

The procalcitonin serum levels are highly correlated with APACHE II, SAPS II and SOFA severity scores used in intensive care units and can therefore be used for determining the severity of the septic process.

Quantitive procalcitonin and C-reactive protein analysis did not indicate their usefulness in the diagnosis of severe sepsis, however procalcitonin can be used for predicting the fatal outcome of the septic patient.

\section{ACKNOWLEDGEMENTS}

This paper is supported by the Sectoral Operational Programme Human Resources Development (SOP HRD), financed from the European Social Fund and by the Romanian Government under the contract number POSDRU/159/1.5/S/133377.

\section{口CONFLICT OF INTEREST}

The authors declare that they have no conflict of interest.

\section{ABbreviations}

APACHE II - Acute physiology and chronic health evaluation

AUC - Area under curve

BMI - Body mass index

COPD: chronic obstructive pulmonary disease

$\mathrm{CRP}$ - $\mathrm{C}$ reactive protein

ELISA - Enzyme-linked immunosorbent assay

MRSA - Methicilin resistant staphylococcus aureus

PCT - Procalcitonin

SAPS - Simplified acute physiology score

SIRS - Systemic inflammatory response syndrome

SOFA - Sequential Organ Failure Assessment

\section{DEFERENCES}

1. Angus DC, Linde-Zwirble WT, Lidicker J, et al. Epidemiology of severe sepsis in the United States: Analysis of incidence, outcome, and associated costs of care. Crit Care Med. 2001;29:1303-10.

2. Dellinger RP. Cardiovascular management of septic shock. Crit Care Med. 2003;31:946-55.

3. Bone R, Balk R, Cerra F, et al. Definitions for sepsisand organ failure and guidelines for the use of innovative therapies in sepsis. The ACCP/SCCM Consensus Conference Committee. 
Available online at: www.jccm.ro

American College of ChestPhysicians / Society of Critical Care Medicine". Chest. 1992;101: 1644-55.

4. Linde-Zwirble WT, Angus DC. Severe sepsis epidemiology: Sampling, selection, and society. Crit Care. 2004;8:222-6.

5. Hervald H, Egesten A. Sepsis. Pro-Inflammatory and AntiInflammatory Responses. Controb Microbiol. Basel, Krager, 2011, vol 17, pp 1-11.

6. Dellinger RP, Levy MM, Rhodes A, et al. Surviving Sepsis Campaign: International guidelines for management of severe sepsisand septic shock: 2012. Crit Care Med. 2013;41:580-637.

7. Giamarellos-Bourboulis EJ, Giannopoulou P, Grecka P, et al. Should procalcitonin be introduced in the diagnostic criteria for the systemic inflammatory response syndrome and sepsis? J Crit Care. 2004; 19:152-7.

8. James D. Faix. Biomarkers of sepsis. Crit Rev Clin Lab Sci. 2013;50:23-36

9. Szederjesi J, Almasy E, Lazar A, Huțanu A, Georgescu A. The Role of Angiopoietine-2 in the Diagnosis and Prognosis of Sepsis. J Crit Care Med. 2015;1:18-23.

10. Schröder J, Staubach KH, Zabel P, Stüber F, Kremer B. Procalcitonin as a marker of severity in septic shock. Langenbecks Arch Surg. 1999;384:33-8.

11. Enguix-Armada A, Escobar-Conesa R, La Torre AG, De La TorrePrados MV. Usefulness of several biomarkers in the management of septic patients: C-reactive protein, procalcitonin, presepsin and mid-regional pro-adrenomedullin. Clin Chem Lab Med. 2015 17. pii: /j/cclm.ahead-of-print/cclm-2015-0243/cclm2015-0243.xml. doi: 10.1515/cclm-2015-0243. [Epub ahead of print]

12. Samraj RS, Zingarelli B, Wong HR. Role of biomarkers in sepsis care. Shock. 2013;40:358-65.

13. Levy MM, Fink MP, Marshall JC, et al; SCCM/ESICM/ACCP/ ATS/ SIS: 2001 SCCM/ESICM/ACCP/ATS/SIS International Sepsis Definitions Conference. Crit Care Med. 2003; 31:1250-6.

14. Vincent JL, Sakr Y, Sprung CL, et al. Sepsis in European intensive care units: results of the SOAP study. Crit Care Med. 2006;34:344-53.

15. Nargis W, Ibrahim Md, Adamed BU. Procalcitonin versus
The Journal of Critical Care Medicine 2015;1(4) • 153

C-reactive protein: Usefulness as biomarker of sepsis in ICU patient. Int J Crit IIIn Inj Sci. 2014;4:195-9.

16. Koenig SM, Truwit JD. Ventilator-Associated Pneumonia: diagnosis, treatment, and prevention. Clin Microbiol Rev. 2006;19:637-57.

17. Magill SS, Dumyati G, Ray SM, Fridkin SK. Evaluating Epidemiology and Improving Surveillance of Infections Associated with Health Care, United States. Emerg Infect Dis. 2015;21:1537-42.

18. Que YA, Guessous I, Dupuis-Lozeron E, et al. Prognostication of Mortality in Critically III Patients With Severe Infections. Chest. 2015;148:674-82.

19. Enguix-Armada A, Escobar-Conesa R, La Torre AG et al. Usefulness of several biomarkers in the management of septic patients: C-reactive protein, procalcitonin, presepsin and midregional pro-adrenomedullin. Clin Chem Lab Med. 2015. pii: /j/cclm.ahead-of-print/cclm-2015-0243/cclm-2015-0243.xml. doi: 10.1515/cclm-2015-0243. [Epub ahead of print].

20. Brun-Buisson C, Doyon F, Carlet J, et al. Incidence, Risk Factors, and Outcome of Severe Sepsis and Septic Shock in Adults. A Multicenter \{rospective Study in Intensive Care Units. JAMA. 1995;274:968-74.

21. Hinriksdóttir G, Tryggvadóttir Á, Ólafsdóttir AS, et al. Fatness but Not Fitness Relative to the Fat-Free Mass Is Related to C-Reactive Protein in 18 Year-Old Adolescents. PLoS One. 2015;10:e0130597. doi: 10.1371/journal.pone.0130597. eCollection 2015.

22. Parrett AL, Valentine RJ, Arngrímsson SA et al. Adiposity, activity, fitness, and C-reactive protein in children. Med Sci Sports Exerc. 2010;42:1981-6.

23. Waheeda Nargis, Md Ibrahim, Borhan Uddin Ahamed. Procalcitonin versus C-reactive protein: Usefulness as biomarker of sepsis in ICU patient. Int J Crit. 2014;4:195-9.

24. Akcay I, Okoh AK, Yalav O, et al. The prognostic value of procalcitonin, CRP and thyroid hormones in secondary peritonitis: a single-center prospective study. Ulus Travma Acil Cerrahi Derg. 2014;20:343-352. 